\title{
Spirituelle Erneuerung mit Emojis
}

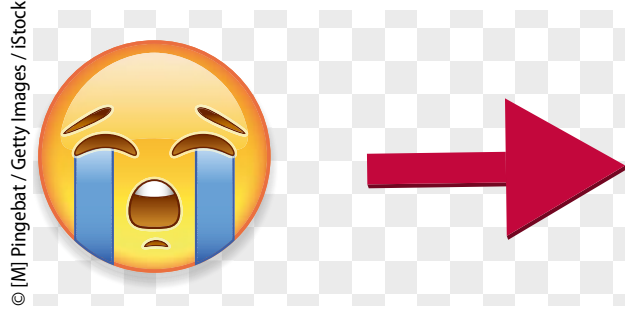

Auf meinem Schreibtisch steht eine Taschentücherbox. Sie ist allerdings weniger für die Schnupfnasen gedacht. Sie dient eher den Verzweifelten und Unglücklichen, wenn sie von ihrem Tränenfluss übermannt werden. Deshalb bemühe ich mich immer, ein nettes, vielleicht sogar Trost spendendes Motiv auf der Box zu präsentieren.

Neulich stieß ich im Supermarkt auf einen Karton, der mit Emojis bedruckt war, diesen kleinen Smiley-Piktogrammen, die bekanntermaßen alle Gefühle ausdrücken können. Der musste mit.

Schon am nächsten Tag fand sich die erste Benutzerin ein: Die Tränen flossen unaufhörlich, und die Taschentücher wurden bis zum Boden aufgebraucht. Es war nun bereits das dritte Gespräch, das wir über ihr Problem führten: Sie, eine junge, schöne, hochrangige Wissenschaftlerin, fand einfach keinen neuen Arbeitsplatz in der Schweiz, dem Land der schneebedeckten Berge. Dortselbst allerdings hockte ihr Freund, ebenfalls beruflich hochqualifiziert und ebenfalls unfähig sich aus seiner Lebenssituation zu lösen.

Wir hatten das Thema schon mehrfach durch.

Ich ließ mich nun von den Emojis inspirieren, die ihre Botschaften so kurz und bündig vermitteln. Ich zückte ein Privatrezept, zeichnete zwei Ringe darauf und schrieb die Vornamen der unglücklich Getrennten darunter. Liebe ist die beste Medizin, dachte ich mir.

Ich weiß nicht, ob es meine VoodooKritzelei war, aber keine vier Wochen später bekam ich einen neuen Patienten aus der Schweiz. Er hatte eine Stelle in Darmstadt bekommen! Das macht in meinen Augen drei Smileys: einen lachenden mit Herzchenaugen, einen lachenden und zwinkernden - und für mich den fröhlichen mit der herausgestreckten Zunge.

Dr. Luise Hess, Darmstadt

\section{Das Märchen von Dr. Holle}

_ Mein Patient aus Persien wollte eine Überweisung für Dr. Holle. „Für wen?“, fragte ich einigermaßen ungläubig „Dr. Hooolle“, belehrte er mich, und zückte sodann einen Facharztbericht mit Adresse. Tatsächlich: Dr. Holle.

„Kennen Sie denn auch das Märchen der Gebrüder Grimm von Frau Holle?“, fragte ich mein Gegenüber, begierig auf interkulturellen Austausch und Bereicherung. Er kannte es nicht. Dem Manne wollte geholfen werden, und so berichtete ich ihm so gut es ging den Inhalt der alten Geschichte.
Als ich mit dem Erzählen fertig war, strahlte mich mein Patient an. „Das muss ich Dr. Holle erzählen“, rief er aus. „Müssen Sie nicht, das Märchen kennt er schon“, meinte ich - davon ging ich jedenfalls aus.

Zum Dank bekam ich dann von Scheherezade berichtet, der Tochter des persischen Königs Schahrayar, die mit ihren Geschichten, den „Märchen aus 1001 Nacht“, den blutrünstigen Sultan Scheherban besänftigte. So märchenhaft kann Sprechstunde sein.

Dr. Luise Hess, Darmstadt

\section{Enthusiastische Aufforderung zur digitalen Untersuchung}

Selbst nach Jahrzehnten als Hausarzt gibt es immer noch verrückte Momente, die das alberne Schulkind in einem hervorbringen. So wie bei dem 86-jährigen Patienten mit schwachem Urinstrahl, der selbst auf die Idee kam, woran es liegen könnte: „Es ist wohl die Protasta!", exklamierte er. War das nur ein Versprecher, oder sah ich dort ein Glitzern in seinen Augen? Jedenfalls kam ich dieser indirekten Aufforderung sogleich und mit einem nur schwer unterdrückbarem Lachanfall nach.

Dr. Herbert Zimmer, Freiburg 